Publisher: Taylor \& Francis \& IA HS

Journal: Hydrological Sciences J ournal

DOI: 10.1080/02626667.yyyy.nnnnnn

\title{
A comparative study for water temperature modelling in a small basin, the
}

\section{Fourchue River, Quebec, Canada}

\author{
Jaewon $\mathrm{K}$ wak $^{1}$, A ndre, St-Hilaire ${ }^{2}$ and Fetah Chebana ${ }^{2}$
}

${ }^{1}$ Nakdong River Flood Control Office, B usan, South K orea,
2INRS-ETE, INRS, Quebec, Canada,
Corresponding author : A. St-Hilaire: email: Andre.St-Hilarie@ ete.inrs.ca

Comment [F1]: Check!

\begin{abstract}
Analysis and forecasting of water temperature are important for water-ecological
\end{abstract} management. The objective of this study is to compare models for water temperature during the summer season for an impounded river. In a case study, we consider hydro-climatic and water temperature data of the Fourchue River (St-A lexandre-de-Kamouraska, Quebec, Canada) from between 2011 to-and 2014. Three different models were applied, which are broadly characterized as deterministic (CEQUEAU), stochastic (A uto-regressive M oving Average with eX ogenous variables or ARMAX) and nonlinear (Nonlinear Autoregressive with eXogenous variables or NARX). The efficiency of each model was analyzed and compared. The rResults show that the ARM AX is the best performing water temperature model for the Fourchue River and the CEQUEAU model also simulated water temperature adequately without the overfitting issues that seem to plague the autoregressive models.

Keywords water temperature; CEQUEAU; ARMAX; NARX

\section{INTRODUCTION}

Water temperature affects physical and biological processes in the river system and is one of the most important physical characteristics for aquatic organisms (B eschta et al ${ }_{. \bar{\tau}^{\prime}}$ 1987 $_{\mathbf{L}^{\prime}} \mathrm{Hammitt}$ and

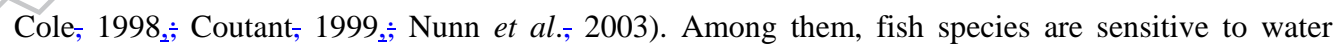
temperature for growth rate and spawning (Ojanguren et al., 2001; Selong et al., 2001; Lessard and 
Hayes, 2003; Handeland et al., 2008). Furthermore, it is also an important factor for water quality (Singh et al., 2004; M orrill et al., 2005; Chang, 2008). There are many models and studies which contribute to more accurate water temperature simulations and forecasts. Caissie (2006) suggested that most models can be classified into three categories: regression-based, deterministic and stochastic. Following the early work of J ohnson (1971) and Kothandaraman (1972), parametric statistical models such as regressions have been applied in many studies (Benyahya et al., 2007a). Simple linear regressions have been used with air temperature as a predictor (Crisp and Howson, 1982; M ackey and Berrie, 1991; Stefan and Preud'H omme. 1993). A Iso, multiple regression (J eppesen and Iversen, 1987; Jourdonnais et al., 1992), logistic regression (M ohseni et al., 1998; M ohseni and Stefan, 1999), ridge regression (A hmadi-N edushan et al, 2007) and Gaussian-process regression ( $\mathrm{Grb} \cdot$ et al, 2013) have been used in water temperature models.

Deterministic models are based on the governing laws of heat exchanges and they consider the different energy fluxes and (in some cases) mixing process in the rivers with various degrees of complexity (M orse, 1970; Caissie, 2006, 2007). Due to this, they are widely used in applications with complex thermal in/outflows (Sinokrot and Stefan, 1993; Kim and Chapra, 1997; Younus et al., 2000; Danner et al., 2012). However, these models typically require more data than statistical models (B enyahya et al., 2007b). In contrast, stochastic models often require one or few predictors that are correlated with water temperature (Caissie, 1998; Webb et al., 2008). This category of models is very efficient when air temperatures are the only available data (Caissie, 2006). Hence, they have been widely applied to estimate weekly/monthly water temperature (M ohseni et al., 1998; Benyahya et al., 2007b, 2008), daily water temperature (Caissie et al., 1998, 2001; Pal'shin and Efremova, 2005; A hmadi-N edushan etal, 2007; L arnier et al., 2010) and hourly temperature (M estekemper et al., 2010; Pike et al., 2013; , eong et al., 2013). Furthermore, A rtificial neural networks (A NN), which belong to the non-parametric category (Chenard and Caissie, 2008; Sahoo et al., 2009; DeWeber and Wagner, 2013; Hadzima-Nyarko et al., 2014), k-nearest neighbors algorithm (k-NN), which is a nonlinear dynamic model (Benyahya et al., 2008; Nowak et al., 2010; St-Hilaire et al., 2012; Caldwell et al., 2013) and dynamic chaotic models (Sahoo et al., 2009) have been applied to estimate water temperature. While the literature on water temperature modelling is growing rapidly, relatively few 
comparative modelling studies have been completed on rivers with dams, especially in Canada.

The objective of this study is therefore to investigate the simulation efficiency of a number of water temperature models using hydro-climatic variables in the context of regulated flows. The models were compared on the Fourchue River basin, a forested catchment on which there is a managed reservoir. The Fourchue River has been previously studied by Beaupré (2014). She compared a deterministic model (SNTEM P; B artholow, 1995) and a geostatistical model (Guillemette et al., 2009) both upstream and downstream of the dam. B eaupré (2014) showed that the geostatistical model outperformed SNTEMP for directly predicting temperature metrics that are relevant for salmonids, especially when these metrics are calculated using simulated maximum temperatures. For this follow-up study, hydro-climatic data were collected from 2011 to 2014 and models that represent three categories: deterministic, stochastic and nonlinear were used.

\section{STUDY AREA AND DATA}

The Fourchue River, with a drainage basin of $261 \mathrm{~km}^{2}$, is a tributary of the Du-L oup River, located in the eastern Quebec region, Canada. The Fourchue River is regulated by the M orin Dam, with flows of between 0.06 to-and $4.0 \mathrm{~m}^{3} /$ which discharged from the epilimnion zone of the reservoir (184 E.L.m.to 188 E.L.M).

\section{Fig. 1 Study area and measuring station.}

Many factors influence water temperature variability, which can be classified into four groups; atmospheric, topographic, hydrologic and streambed conditions. Selected predictors included atmospheric variables because atmospheric conditions are mainly responsible for the heat exchange processes. In addition, stream discharge was selected because it influences the heating capacity by determining the volume of water in the river reach (Caissie, 2006), but also because all models compared in this study need to be able to account for the impact of impoundment and the associated regulated flows. 
A tmospheric variables used as potential predictors include air temperature, solar radiation, relative humidity and wind speed, which are known to be related to water temperature. Water temperature were obtained during the summer seasons (J une to September) from 2011 to 2014 with Hobo Pro V2 thermographs $\left( \pm-0.2_{-}^{\circ}-{ }^{\circ} \in \underline{C}\right)$ sampling at $15--$ minutes intervals, and hourly solar radiation data were measured with a Kipp and Zonen pyranometer (SP-LITE, $\pm 10 \mathrm{uV} / \mathrm{W} / \mathrm{m} 2$ ), connected to a Campbell Scientific CR 1000 datalogger, powered by a solar panel and a 12--V battery. The water temperature loggers were deployed over a 8--km river reach, from directly downstream of the Morin Ddam to its confluence with the Du-Loup River. Air temperature and relative humidity were obtained from the Fourchue River meteorological station (Environment Canada; http://climate.weather.gc.ca). Also, hydro-physiographic properties of the Fourchue River basin, required to run the deterministic model, were extracted from a $3 \mathrm{~km} * 3 \mathrm{~km}$ grid DEM and IL-and-use map (http://srtm.csi.cgiar.org/) (Fig.ure 2).

Fig. 2 Hydro-physiographical characteristics of the study area-, showing Map shows-land use, whole squares (elementary hydrological units) and arrows indicateing water routing used for the deterministic (CEQUEAU) model.

\section{METHODOLOGY}

\subsection{Test statistics for selection of model and predictors selection}

Given the plethora of potential models, five test statistics were used to identify the main characteristics of collected temperature data and potential predictors in order to select reasonable candidate models to simulate water temperatures of the Fourchue River. The considered tests are: the Spearman rank correlation coefficient for randomness (M yers and Well, 2003), the Ljung-B ox Q test for autocorrelation (Ljung, 1978), Levene's test for heteroscedasticity (Levene, 1960), the Lyapunov exponent test (B ask and Gençay, 1998) and the BDS statistics test for chaotic characteristic (B rock et 
al. 1987) of data time series.

Mutual Information (I) was also used to select appropriate predictors among the collected data set $_{\bar{F}_{2}}$ where $I(X: Y)$ is a measure of the amount of information that one continuous random variable $X$ contains about another continuous random variable Y (Cover and Thomas, 2006):

$$
\mathrm{I}(\mathrm{X}: \mathrm{Y})=\int_{Y} \int_{X} p(x, y) \log \left(\frac{p(x, y)}{p(x) p(y)}\right) d x d y
$$

where, $p(x)$ and $p(y)$ are the marginal probability density functions of $\mathrm{X}$ and $\mathrm{Y}$ and $p(x, y)$ is the joint probability density function. The mutual information will be larger for variables which have a stronger relation and vice versa. So, predictors selection based on value of $I(X: Y)$ of each input variable with the output variable can be used to identify the most important predictors (B attiti, 1994).

\subsection{Water $\underline{\mathbf{t} F e m p e r a t u r e ~} \underline{\mathbf{m}}$ Models}

Given the large number of available water temperature models in use, the aforementioned criteria were used to find the most suitable ones for the Fourchue River. Three types of candidate

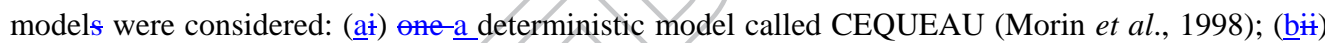
the ARM AX (A autoRfegressive-M moving Aaverage with $\mathrm{X}$ X $*$ ogenous terms) model, which is in the stochastic category; and (ciii) the NARX (N onlinear A utoRegressive model with eX ogeneous input) for the nonlinear approach.

The CEQUEAU model is a hydrological model that is combined with a heat budget model and has shown applicability in Canada (M orin and Slivitzky, 1992; St-Hilaire et al., 2000, 2003; Seiller and Anctil, 2014) and in other countries (Dibike and Coulibaly, 2005; Ba et al., 2009; Sauquet et al., 2009; Eleuch et al., 2010). The A RM AX model is useful when the data are noisy, so it has the potential to show good results and provide flexibility in describing the properties of the noise associated with water temperature time series (Breaker and Brewster, 2009) and NARX models also show good performance for several types of chaotic time series (Diaconescu, 2008). 


\subsubsection{CEQUEAU model: deterministic approach}

The CEQUEA U model is a semi-distributed hydrologic model which takes into account the hydro-physiographic characteristics of the basin (M orin et al., 1981). It is based on a water balance calculations and subsequent runoff generation through a set of elementary hydrological units called "whole squares", which are further divided in "partial squares" according to the water divide (M orin et al., 1998). The CEQUEAU model comprises two functions to describe the runoff mechanism and upstream-downstream routing: (a) the production function represents vertical water routing from rainfall, snow melt, infiltration and evapotranspiration used in water-balance calculations, and (b) the routing function is used to estimate the amount of water transiting to the downstream partial squares and ultimately to the outlet of the basin in the drainage network (Figure 3)

Fig. 3 Schematic description of CEQUEAU model $: \frac{i}{i}$ (a) production function (b) routing

$$
\text { function (M orin, 2007). }
$$

Prior to modelling water temperature, the hydrological model component of CEQEAU needs to be calibrated against observed flows and/or water levels. M odel parameters were adjusted by hand using water level and runoff data of the Morin Dam between J une 2011 and September 2014 (Figure 4). Subsequently, the water temperature module of the CEQEAU model was used (M orin et al, 1998). This component computes a heat budget on each elementary hydrological unit (whole squares) based on the volume of water modelled by the hydrological module of CEQUEAU. Heat budget terms include incoming short wave solar radiation, net longwave radiation, latent heat, sensible heat, heat advected from upstream, heat loss downstream and local contributions from groundwater and interflow. Each heat budget term can be adjusted using a weighing coefficient. Average water temperatures are thus estimated at a daily time step.

Fig. 4 Observed and simulated flows with CEQUEAU hydrological model for both 
calibration and validation periods (J une 2011 to September ${ }_{\bar{i}}$ 2014).

\subsubsection{ARMAX: stochastic approach}

The ARMAX model is useful when the input data have noise, has more flexibility than other stochastic model, such as ARM A or ARX, and is defined as:

$$
\mathrm{A}(z) y(t)=B(z) u(t-k)+C(z) e(t)
$$

wWhere $y(t)$ is the output, $u(t)$ is the input, $e(t)$ is the system error and $k$ is the time delay of the system. The terms $A(z), B(z)$, and $C(z)$ are polynomial with respect to the backward shift operator $z^{-1}$ and defined as:

$$
\begin{gathered}
\mathrm{A}(z)=1+a_{1} z^{-1}+\cdots+a_{t_{a}} z^{-t_{a}} \\
\mathrm{~B}(\mathrm{z})=b_{0}+b_{1} z^{-1}+\cdots+b_{t_{b}} z^{-\left(t_{b}-1\right)} \\
C(z)=1+c_{1} z^{-1}+\cdots+c_{t_{c}} z^{-t_{c}}
\end{gathered}
$$

In this study, the ARMAX model has second order AR and MA processes and one day time $\operatorname{lag}(k)$, which were optimized by trial and error method $(\operatorname{ARMAX}(2,2,1))$.

\subsubsection{NARX-: nonlinear approach}

Non-linear A utoRegressive model with eXogeneous input (NARX), is a special form of recurrent neural network with the outputs fed back to the input by delay line (Haykin, 1999). It has been demonstrated that they are well suited for modeling nonlinear and chaotic time series ( Lin et al, 1996; Gao and J 00, 2005) and also solve vanishing gradient problem, which occur in the prediction of nonlinear data (Haykin, 1999). A NARX model can be expressed as (Eq(4) and Figure 5):

$$
y_{t}(t+1)=\left\{\begin{array}{lr}
\varnothing\left(u(t), y_{i}(t),\right. & i=1 \\
y_{i}(t), & i=2,3, \ldots, k
\end{array}\right\}
$$


WW-here the output $y_{t}(t+1)$ and $y_{i}(t), i=1,2, \ldots, k$, are state variables of a recurrent neural network that contains feed-back connection for water temperature of the previous time step. $t$ denotes the time series index set and $\varnothing$ denotes the neural network system. The LevenbergM arquardt-QNB P algorithm was used to train the network and to optimize the parameters. It is known to show good results for non-linear problems such as related meteorological and hydrological data (B attiti, 1989). NARX model of this study has 12 hidden layers that include one feed-back layer with one day time lag $(k)$ for water temperature.

Fig. 5 NARX network schematization (Jose et al., 2008), where- $u(t)$ is the input set, $y_{i}(t)$ is the exogeneous input, $\mathrm{k}$ is the input delay and each circle represents an artificial neuron.

To compare the results of each model, R oot Mean Square Error (RM SE (Root Mean Square Error; Hyndman and Koehler, 2006; Eq. 5), Bias (Eq. 6) and N ash--Sutcliffe_-model efficiency coefficient of model efficiency (E; N

$$
\begin{aligned}
& \text { RMSE }=\sqrt{\frac{\sum_{i=1}^{n}\left(O_{o b s}-O_{\text {sim }}\right)^{2}}{n}} \\
& \text { Bias }=\frac{\sum_{i=1}^{n}\left(O_{o b s}-O_{s i m}\right)}{n} \\
& \text { Nash } \mathrm{E}=1-\frac{\sum_{i=1}^{n}\left(O_{o b s}-O_{s i m}\right)^{2}}{\sum_{i=1}^{n}\left(O_{o b s}-\overline{O_{o b s}}\right)^{2}}
\end{aligned}
$$

where $O_{o b s}$ and $O_{s i m}$ are the observed and simulated values at the same time step, $\overline{O_{o b s}}$ denotes mean value of $O_{\text {obs }}, n$ denotes the number of observations. The RM SE describes an average measure of the error in prediction but it doesn't provide any information on phase differences. The bias represents the mean of all the individual errors and shows whether the model over or under estimates. The Nash-_-Sutcliffe model efficiency coefficient, $E_{\text {, }}$, has been widely_-used_-to assess the

\section{Formatted: Font: Italic}

Comment [F9]: You have referred to the Nash-Sutcliffe efficiency here and in equ (7) as $E$, yet in the figures and elsewhere in the text and/or figures it is Nash, or NASH. Please use one consistent term (see Guidelines on units and notation)

Formatted: Font: Italic

Comment [F10]: See earlier

comment about equations/maths - obs and sim should be non italic 
predictive power of hydrological__models (M oriasi et al., 2007).

\section{MODEL AND PREDICTOR SELECTION}

We applied five test statistics (Spearman rank correlation coefficient, Ljung-B ox Q, Levene, Lyapunov exponent and BDS test) to determine the characteristics of the collected data (water and air temperature, runoff, solar radiation, relative humidity and wind speed). Through the Spearman Rank Correlation and Ljung-Box $\mathrm{Q}$ tests, all time series except solar radiation, which is a truly random series (calculated 0.154 versus critical value 1.96 in the Spearman Rank Corr. Coeff. test, and p-value 0.997 in Ljung Box-Q test), were identified as stochastic time series. Other test results are shown in Table 1.

Table 1 Test statistics for each dependent and independent variables.

As the result of test statistics indicate, solar radiation data are categorized as a random series, runoff is a chaotic time series which has heteroskedasticity, relative humidity is also a chaotic time series and other data time series (water temperature, air temperature and wind speed) are categorized as nonlinear stochastic time series. Water temperature (target variable) can be classified as a nonlinear stochastic time series and most of the input predictors are chaotic, nonlinear and stochastic time series. Therefore, models such as multiple regression or zero-mean $A R(1)$ models that cannot account for such characteristics are not eligible to simulate water temperatures in the Fourchue River. From the conclusions drawn from Table 1 , the NARX and ARMAX models were selected because they are adapted to model time series such as water temperature and they show good results with chaotic and nonlinear data (Diaconescu, 2008; Diversi et al., 2011). These models will be compared to the deterministic model (CEQUEAU).

Also, selection of the appropriate inputs is one of the main challenges. For the stochastic models, this selection can be done by trial and error models with different number of input variables (Grbi • et al., 2013). However, that trial and error method can be time-consuming and lead to poor 
performance for neural networks (Haykin, 1999; Maier and Dandy, 2000). So, mutual information theory was employed to select the most important predictor variables for the NARX models. As the result of the computation of mutual information, air temperature (1.28), runoff $(0.82)$ and relative humidity (1.09) are shown to have more meaningful mutual information value with water temperature than solar radiation $(0.30)$ and wind speed (0.09). The positive high value of the mutual information is indicative that the potential predictor has a stronger relation with the dependent variable, i.e. water temperature (M ay et al., 2008; Sahoo et al., 2009). So, air temperature, runoff and relative humidity were selected as the appropriate predictors.

To corroborate the results of the Mutual Information analysis, a trial and error jackknife method was used. One of the hydro-climatic variable was removed from the input data set, which consist of air temperature, runoff, relative humidity, solar radiation and wind speed. Then the NARX and ARMAX models were simulated 200 times with each removed data set. Figure 6 shows boxplots of the evaluation result of simulation with each removed set.

Fig. 6 Performance statistics from jackknife simulations to select predictor $r_{: \frac{;}{i}}(a)$

RMSE of NARX, (b) ENash of NARX, (c) Bias of NARX, (d) RMSE of ARMAX, (e) Nash E of ARMAX, and (f) Bias of ARMAX.

Formatted: Font: Italic

Formatted: Font: Italic

As the mutual information results and boxplots show and as expected, air temperature is the most suitable predictor for water temperature simulation. Runoff and relative humidity are also revealed as suitable independent predictors. The fact that runoff was included in the list of predictors is of the utmost importance, given that the river is regulated and that the models must be able to account for flow management. On the contrary, the inclusion of solar radiation and wind speed showed no improvement and in some cases, slightly better results were obtained if they were removed from the input data set.

Also, as shown in Ffig.ufe 4, the summer season (J une-to-_September-) of 2011 has a high runoff event (peaking at over $30 \mathrm{~m}^{3} / \mathrm{s}$ ), while the other periods do not include such extreme events (i.e. 
flows remain below $10 \mathrm{~m}^{3} / \mathrm{s}$ ). In spite of the inclusion of flow as a predictor, model performances are not as good during high runoff period as for the rest of the time. Longer time series will be required to improve model calibration on the Fourchue River.

\section{RESULT $\underline{S}$ AND DISCUSSION}

To partially overcome the challenges associated with the relatively small time series that can be used form model calibration, we divided the data set in two cases and perform calibration and validation in both cases.

Case 1: 2011, 2012, 2013 as calibration period and 2014 as validation period.

Case 2: 2012, 2013, 2014 as calibration period and 2011 as validation period.

The calibration results with selected models and predictors, which consist of air temperature, runoff and relative humidity, are shown in Ffigures 7 and 8.

Fig. 7 Calibration results for C ase $1: \div$ (a) CEQUEA U model, (b) ARMAX, (c) NARX.

Formatted: Font: Not Italic

Fig. 8 Calibration results for Case 2:- (a) CEQUEAU model, (b) ARMAX, (c) NARX.

The ARMAX model shows the best results among all the selected models, with an RMSE, Bias and $\mathrm{N}$ ash values of $0.56-^{\circ} \mathrm{C}, 0.03-{ }^{\circ} \mathrm{C}$ and $0.96_{\perp}$ respectively $\mathrm{L}_{L}$ during the calibration period. It is closely followed by the other model with an autoregressive component, i.e. the NARX model (see with ' $E$ ' Table 2). The CEQUEAU model simulation is characterized by a larger bias than the statistical models in cases 1 and 2, mostly caused by an underestimation of the warm period in 2012. Validation results are shown in Figures 9 and 10 and performance metrics are provided in Table 2. As it is often the case, all models show higher RM SE and lower Nash coefficient values for the validation than the calibration phase, except for the CEQUEAU model, which shows similar results for both calibration 
and validation phases albeit with a higher bias (Table 2). Overall, the ARMAX model has the best performance, in spite of a slightly higher RMSE and lower NASH value than the deterministic model during one validation phase (in Case 2, Table 2).

Fig. 9 Validation results for Case $1_{: ;}$(a) CEQUEAU model, (b) ARMAX, (c) NARX.

Fig. 10 Validation results for Case 2; (a) CEQUEAU model, (b) ARMAX, (c) NARX.

Table 2 Calibration and validation performance statistics for each Case.

The CEQUEAU model showed some modeling potential, in spite of a systematic negative bias $\left(-0.41^{\circ} \mathrm{C}\right.$ for calibration and $-1.06^{\circ} \mathrm{C}$ for validation phase). It $/$ seems that the proximity of the monitoring station to the dam, may be one cause of the bias. The thermal regime in the Fourchue River is very strongly influenced by the presence of the reservoir. The travelling time is very short between the dam and the monitoring station ( $<-0.5$ day) and thus, the reservoir thermal regime, which affects the thermal regulation in the lower reach of the Fourchue River, may come into play. For instance, there may be some occasional stratification and mixing of the water column in the reservoir that may modulate the temperature of the discharged water. Such an affect is not accounted for by CEQUEAU. In order to account for stratification, CEQUEAU would need to be coupled to a lake or reservoir temperature model. If stratification were present, it would also affect the ARMAX and NARX models. However, in spite of the fact that water was drawn from the reservoir epilimnion, stratification and mixing may have been an occasional source of error.

Also, in the validation result of Case 2 (Figure 10), all of the selected models, except CEQUEAU show highly over and under estimated water temperatures between August 27 August, 2011 to and September 8 - September 2011 (Figure 10(b) and 10(c)). The high rainfall-runoff events in 2011 seem to be one of the causes of this discrepancy (Figure 4).

Given their autoregressive structure, the ratio of the training sample size to the number of 
weights is 29 (Wang et al., 2005) and overfitting may have occurred for ARM AX and NARX during the calibration phase in Case 2. If this is the case, these models may lack the required robustness to be operationally implemented. Longer time series would be required to fully investigate this. This phenomenon shows the potential disadvantage of the statistic and stochastic models. The CEQUEAU model shows worse results than ARMAX and NARX model, but its performance is more constant throughout the calibration and validation periods, with $0.8^{\circ} \mathrm{C}$ in RMSE and 0.9 in Nash coefficient (Table 2). O therwise, the deterministic model (CEQUEAU) will be good alternative when the hydroclimatic data has extreme events which are expected as the cause of overfitting issue.

\section{CONCLUSION $\underline{S}$}

This study performed a comparative analysis of three models used to simulate water temperatures in the Fourchue River, Quebec, Canada. The main conclusions are:

1. As shown by the result of test statistics, water temperature data and most input variables of the Fourchue River were proven to be chaotic, nonlinear and stochastic time series. Simple statistic models such as linear regression may prove to be inadequate. For this reason, more sophisticated time series models (ARM AX and NARX) were tested.

2. The CEQUEAU showed weaker performances than ARMAX and NARX, with systematic bias. But its performance is constant throughout with $0.8^{\circ} \mathrm{C}$ in RM SE and 0.9 in $\mathrm{N}$ ash coefficient and there is no indication of overfitting.

3. The fact that the ARMAX model proved to have the best performance is not surprising, given the non-linear autoregressive nature of the model. Water temperatures in any river have strong autocorrelation. This phenomenon is exacerbated in the Fourchue River, because of the presence of the reservoir, which has a strong dampening effect.

4. Two models except CEQUEAU show potential overfitting, as shown by their weaker performance in the validation phase in Case 2. Therefore, the CEQUEAU model (deterministic approach) will expect the stable performance for the Fourchue River. 


\section{Acknowledgements}

This work was supported by the NSERC HY DRONET strategic network.

\section{References}

A hmadi-Nedushan, B., St-Hilaire, A., Ouarda, T. B., Bilodeau, L., Robichaud, E., Thiemonge, N. and Bobee, B ., 2007. Predicting river water temperatures using stochastic models: case study of the M oisie River (Québec, Canada). H ydrological Processes, 21(1), 21-34.

Ba, K. M., Quentin, E., Carsteanu, A. A ., Ojeda-Chihuahua, I., Diaz-Delgado, C. and Guerra-Cobian, V. H., 2009. M odelling a large watershed using the CEQUEAU model and GIS: The case of the Senegal River at Bakel. In EGU General Assembly Conference Abstracts, 11, 11839.

Bartholow, J.M., 1995. The stream network temperature model (SNTEMP): A decade of results. Workshop on Computer Application in Water Management. Fort Collins, Co: Water Resources Research Institute, CSU. U.S. Geological Survey.

Battiti, R., 1994. Using mutual information for selecting features in supervised neural net learning. IEEE Transactions on Neural Networks, 5(4), 537-550.

Battiti, R., 1989. A ccelerated backpropagation learning: Two optimization methods, Complex systems, 3(4), 331-342.

Bask, M. and Gençay, R., 1998. Testing chaotic dynamics via Lyapunov exponents. Physica D: Nonlinear Phenomena, 114(1), 1-2.

Beschta, R. L., Bilby, R. E., B rown, G. W., Holtby, L. B. and Hofstra, T. D., 1987. Stream temperature and aquatic habitat: fisheries and forestry interactions. Streamside management: forestry and fishery interactions, 57, 191-232.

B enyahya, L., St-Hilaire, A., Q uarda, T. B., B obée, B. and A hmadi-N edushan, B ., 2007a. M odeling of water temperatures based on stochastic approaches: case study of the Deschutes River. J ournal of Environmental Engineering and Science, 6(4), 437-448.

Benyahya, L., Caissie, D., St-Hilaire, A., Ouarda, T. B. and B obée, B., 2007b. A review of statistical 
water temperature models. Canadian Water Resources J ournal, 32(3), 179-192.

Benyahya, L., St-Hilaire, A., Ouarda, T. B., Bobee, B. and Dumas, J., 2008. Comparison of nonparametric and parametric water temperature models on the Nivelle River, France. Hydrological Sciences J ournal, 53(3), 640-655.

Beaupré, L., 2014. Comparaison de modèles thermiques statistique et déterministe pour L'estimation d'indices thermiques sur les portions aménagées et naturelles de la rivière Fourchue (Québec, Canada). Thesis (M. Sc.), INRS-ETE.

B reaker, L. C. and Brewster, J. K., 2009. Predicting offshore temperatures in M onterey Bay based on coastal observations using linear forecast models. 0 cean M odelling, 27(1), 82-97.

Brock, W. A., Dechert, W. D. and Scheinkman, J. A., 1987. A Test for Independence Based on the Correlation Dimension. Department of Economics, University of Wisconsin at Madison, University of Houston, and University of Chicago. Social Science Research Working Paper, 8762.

Caldwell, R. J., Gangopadhyay, S., B ountry, J., Lai, Y. and Elsner, M. M., 2013. Statistical modeling of daily and subdaily stream temperatures: Application to the Methow River Basin, Washington. Water Resources Research, 49(7), 4346-4361.

Caissie, D., El-Jabi, N. and St-Hilaire, A ., 1998. Stochastic modelling of water temperatures in a small stream using air to water relations. Canadian J ournal of Civil Engineering, 25(2), 250-260.

Caissie D., El-J abi N. and Satish M.G., 2001. Modelling of maximum daily water temperatures in a small stream using air temperatures. J ournal of H ydrology, 251(1), 14-28.

Caissie, D., 2006. The thermal regime of rivers: a review. F reshwater Biology, 51(8), 1389-1406.

Caissie, D., Satish, M. G. and El-J abi, N., 2007. Predicting water temperatures using a deterministic model: application on Miramichi River catchments (New Brunswick, Canada). J ournal of ( Hydrology, 336(3), 303-315.

Chang, H., 2000. Spatial analysis of water quality trends in the Han River basin, South Korea. Water Research, 42(13), 3285-3304.

Chenard, J.F. and Caissie, D., 2008. Stream temperature modelling using artificial neural networks: application on Catamaran Brook, New Brunswick, Canada. Hydrologic Process. 22(17), 
$3361-3372$.

Coutant C.C., 1999. Perspective on Temperature in the Pacific Northwest's F resh Water. Environmental Sciences Division, Oak Ridge National Laboratory, ORNL/TM -1999/44. Oak Ridge National Laboratory, Oak Ridge, Tennessee, 109.

Cover, T. M. and Thomas, J. A., 2006. Elements of information theory. Hoboken, NJ, USA: John Wiley \& Sons, Inc.. http://dx.doi.org/10.1002/047174882X.

Crisp D.T. and Howson G., 1982. Effect of air temperature upon mean water temperature in streams in the north Pennines and English Lake District. F reshwater Biology, 12(4), 359-367.

Danner, E. M., M elton, F. S., Pike, A., Hashimoto, H., M ichaelis, A., Rajagopalan, B. and Nemani, R. R., 2012. River temperature forecasting: A coupled-modeling framework for management of river habitat. Selected Topics in Applied Earth Observations and Remote Sensing, IEEE J ournal, 5(6), 1752-1760.

DeWeber, J. T. and Wagner, T., 2014. A regional neural network ensemble for predicting mean daily river water temperature. J ournal of $\mathrm{H}$ ydrology, 517(1), 187-200.

Diversi, R., Guidorzi, R. and Soverini, U., 2011. Identification of A RMAX models with noisy input and output. In World Congress, 18(1), 13121-13126.

Diaconescu, E., 2008. The use of NARX neural networks to predict chaotic time series. WSEAS Transactions on Computer Research, 3(3), 182-191.

Dibike, Y. B. and Coulibaly, P., 2005. Hydrologic impact of climate change in the Saguenay watershed: comparison of downscaling methods and hydrologic models. Journal of hydrology, 307(1), 145-163.

Eleuch, S., Carsteanu, A., Bâ, K., Magagi, R., Goïta, K. and Diaz, C., 2010. Validation and use of rainfall radar data to simulate water flows in the Rio Escondido basin. Stochastic Environmental Research and Risk Assessment, 24(5), 559-565.

Gao, Y. and Er, M.J., 2005. NARMAX time series model prediction: feedforward and recurrent fuzzy neural network approaches. F uzzy sets and systems, 150(2), 331-350.

Grbi•, R., Kurtagi•, D. and Sliakovi•, D., 2013. Stream water temperature prediction based on 
Gaussian process regression. Expert Systems with Applications, 40(18), 7407-7414.

Guillemette, N., A. St-Hilaire, TBMJ Ouarda, N. Bergeron, E. Robichaud et L. Bilodeau., 2009. Feasibility study of a geostatistical model of monthly maximum stream temperatures in a multivariate space. J ournal of hydrology 364(1), 1-12.

Handeland, S. O., Imsland, A. K. and Stefansson, S. 0., 2008. The effect of temperature and fish size on growth, feed intake, food conversion efficiency and stomach evacuation rate of A tlantic salmon post-smolts. Aquaculture, 283(1), 36-42.

Haykin, S., 1999. Neural networks: a comprehensive foundation (second ed.), Prentice hall, Upper Saddle River, N ew J ersey, USA .

Hammitt, W. E. and Cole, D. N., 1998. Wildland recreation: ecology and management. J ohn Wiley \& Sons, Hoboken, NJ, USA.

Hadzima-Nyarko, M ., Rabi, A and Šperac, M ., 2014. Implementation of A rtificial Neural Networks in Modeling the Water-Air Temperature Relationship of the River Drava. Water Resources M anagement, 28(5), 1379-1394

Hyndman, R. J., and K handakar, Y., 2006. Automatic time series for forecasting: the forecast package for R (No. 6/07). M onash U niversity, Department of Econometrics and Business Statistics

J eppesen E. and Iversen T.M ., 1987. Two simple models for estimating daily mean water temperatures and diel variations in a Danish low gradient stream. 0 ikos, 49(1), 149-155.

Jeong, D. I., Daigle, A. and St-Hilaire, A., 2013. Development of a stochastic water temperature model and projection of future water temperature and extreme events in the Ouelle River basin in Québec. Canada. River Research and Applications, 29(7), 805-821.

J ohnson F.A., 1971. Stream temperatures in an al pine area. J ournal of Hydrology, 14(3), 322-336.

Jose M. P. M enezes J r. and Barreto, G. A., 2008. Long-term time series prediction with the NARX network: An empirical evaluation. Neurocomputing, 71(16), 3335-3343

Jourdonnais J.H., Walsh R.P., Pickett F. and Goodman D., 1992. Structure and calibration strategy for a water temperature model of the lower M adison River, M ontana. Rivers, 3(3), 153-169.

Kim K.S. and Chapra S.C., 1997. Temperature model for highly transient shallow streams. J ournal of Hydraulic Engineering, 123(1), 30-40. 
Kothandaraman, V., 1972. Air-water temperature relationshop in illinois. J ournal of the American Water Resources Association, 8(1), 38-45.

Larnier, K., Roux, H., Dartus, D. and Croze, O., 2010. Water temperature modeling in the Garonne River (France). Knowledge and M anagement of Aquatic E cosystems, 398(1), 4.

Lessard, J. L. and Hayes, D. B., 2003. Effects of elevated water temperature on fish and macroinvertebrate communities below small dams. River research and applications, 19(7), 721-732.

Levene, Howard, 1960. Contributions to Probability and Statistics: Essays in Honor of Harold Hotelling. Stanford University Press. 278-292.

Lin, T., Horne, B. G., Tiño, P. and Giles, C. L., 1996. Learning long-term dependencies in NA RX recurrent neural networks, IEEE Trans. Neural Networks, 7(6), 1329-1338.

Ljung G. M. and G. E. P. Box, 1978. On a Measure of a Lack of Fit in Time Series M odels. Biometrika, 65(2), 297-303.

Mackey, A. P. and Berrie, A. D., 1991. The prediction of water temperatures in chalk streams from air temperatures. Hydrobiologia, 210(3), 183-189.

Maier, H. R. and Dandy, G. C., 2000. Neural networks for the prediction and forecasting of water resources variables: a review of modelling issues and applications. Environmental Modelling \& Software, 15(1), 101-124.

May, R. J., Dandy, G. C., Maier, H. R. and Nixon, J. B., 2008. Application of partial mutual information variable selection to ANN forecasting of water quality in water distribution systems. Environmental M odelling \& Software, 23(10), 1289-1299.

M estekemper, T., Windmann, M. and Kauermann, G., 2010. Functional hourly forecasting of water temperature. International J ournal of F orecasting, 26(4), 684-699.

Mohseni O., Stefan H.G. and Erickson T.R., 1998. A nonlinear regression model for weekly stream temperatures. Water Resources Research, 34(10), 2685-2692.

Mohseni O. and Stefan H.G., 1999. Stream temperature/air temperature relationship: a physical interpretation. J ournal of Hydrology, 218(3), 128-141. 
Moriasi, D. N., A rnold, J. G., Van Liew, M. W., Bingner,R. L., Harmel, R. D., Veith, T. L., 2007. M odel Evaluation Guidelines for Systematic Quantification of Accuracy in Watershed Simulations. Transactions of the ASABE, 50 (3), 885-900.

Morin, G. and Slivitzky, M., 1992. Impacts of climatic changes on the hydrological regime: Moisie river case. Revue des sciences de l'eau/journal of water science, 5(2), 179-195.

M orin G, Fortin JP, Lardeau JP, Sochanska W. and Paquette S., 1981. M ode'le CEQUEAU: manuel d'utilisation. INRS-Eau, Ste-Foy, Que'bec, Canada

Morin G, Sochanski W., Paquet P., 1998. Le mode'le de simulation de quantite' CEQUEAU-ONU, Manuel de re'fe'rences. Organisation des Nations-Unies et INRS-Eau. Rapport de recherche no. 519,252

Morin G. and Paquet P., 2007. Mode'le hydrologique CEQUEAU, INRS-ETE, rapport de recherche no. R000926, 458.

Morrill, J. C., Bales, R. C. and Conklin, M. H., 2005. Estimating stream temperature from air temperature: implications for future water quality.Journal of Environmental Engineering, 131(1), 139-146.

M orse, W. L., 1970. Stream temperature prediction model. Water Resources Research, 6(1), 290-302.

Myers, Jerome L.; Well, Arnold D., 2003. Research Design and Statistical Analysis (2nd ed.). Lawrence Erlbaum. 508. ISBN 0-8058-4037-0.

Nash, J. E. and J. V. Sutcliffe, 1970. River flow forecasting through conceptual models part I - A discussion of principles. J ournal of $\mathrm{H}$ ydrology, 10 (3), 282-290.

Nowak, K., J. Prairie, B. Rajagopalan and U. Lall, 2010. A nonparametric stochastic approach for multisite disaggregation of annual to daily streamflow. Water Resources Research, 46, W 08529, doi:10.1029/2009W R 008530.

Nunn, A. D., Cowx, I. G., Frear, P. A. and Harvey, J. P., 2003. Is water temperature an adequate predictor of recruitment success in cyprinid fish populations in lowland rivers?, F reshwater Biology, 48(4), 579-588.

Ojanguren, A. F., Reyes-Gavilán, F. G. and Braña, F., 2001. Thermal sensitivity of growth, food intake and activity of juvenile brown trout. J ournal of thermal biology, 26(3), 165-170. 
Pal'shin, N. I. and Efremova, T. V., 2005. Stochastic M odel of the Annual Cycle of Water Surface Temperature in Lakes. Russian M eteorology and Hydrology, 3(1), 61-68.

Pike, A ., Danner, E., Boughton, D., M elton, F., Nemani, R., Rajagopalan, B. and Lindley, S., 2013. Forecasting river temperatures in real time using a stochastic dynamics approach. Water Resources Research, 49(9), 5168-5182.

Sahoo, G. B., Schladow, S. G. and Reuter, J. E., 2009. Forecasting stream water temperature using regression analysis, artificial neural network, and chaotic non-linear dynamic models. J ournal of Hydrology, 378(3), 325-342.

Sauquet, E., D upeyrat, A., Perrin, C., A gosta, C., Hendrickx, F. and Vidal, J. P., 2009. Impact of business-as-usual water management under climate change for the Garonne catchment (France). In IOP Conference Series: Earth and Environmental Science, 6(29), 292009.

Seiller, G. and A nctil, F., 2014. Climate change impacts on the hydrologic regime of a Canadian river: comparing uncertainties arising from climate natural variability and lumped hydrological model structures. Hydrology and Earth System Sciences, 18(6), 2033-2047.

Selong, J. H., M cM ahon, T. E., Zale, A. V. and Barrows, F. T., 2001. Effect of temperature on growth and survival of bull trout, with application of an improved method for determining thermal tolerance in fishes. Transactions of the American Fisheries Society, 130(6), 1026-1037.

Singh, K. P., Malik, A., M ohan, D. and Sinha, S., 2004. Multivariate statistical techniques for the evaluation of spatial and temporal variations in water quality of Gomti River (India)- a case study. Water research, 38(18), 3980-3992.

Sinokrot B.A. and Stefan H.G., 1993. Stream temperature dynamics: measurements and modeling. Water Resources Research, 29(7), 2299-2312.

Stefan, H. G. and Preud'Homme, E. B., 1993. Stream temperature estimation from air temperature. J ournal of the American Water Resources Association, 29(1), 27-45.

St-Hilaire, A., M orin, G., El-Jabi, N. and Caissie, D., 2000. Water temperature modelling in a small forested stream: implication of forest canopy and soil temperature. Canadian J ournal of Civil Engineering, 27(6), 1095-1108.

St-Hilaire, A., El-Jabi, N., Caissie, D., and M orin, G., 2003. Sensitivity analysis of a deterministic 
water temperature model to forest canopy and soil temperature in Catamaran Brook (New B runswick, Canada). Hydrological processes, 17(10), 2033-2047.

St-Hilaire, A., Ouarda, T. B., Bargaoui, Z., Daigle, A. and Bilodeau, L., 2012. Daily river water temperature forecast model with ak-nearest neighbour approach. Hydrological Processes, 26(9), 1302-1310.

St-Hilaire, A., Ouarda, T. B., Bargaoui, Z., Daigle, A. and Bilodeau, L., 2012. Daily river water temperature forecast model with ak-nearest neighbour approach. Hydrological Processes, 26(9), 1302-1310.

Wang, D. and Huang, J., 2005. N eural netw ork-based adaptive dynamic surface control for a class of uncertain nonlinear systems in strict-feedback form. Neural Networks, IEEE Transactions on, 16(1), 195-202.

Webb, B. W., Hannah, D. M., M oore, R. D., Brown, L. E. and Nobilis, F., 2008. Recent advances in stream and river temperature research. Hydrological Processes, 22(7), 902-918.

Younus M., Hondzo M. and Engel B.A., 2000. Stream temperature dynamics in upland agricultural watershed. J ournal of Environmental Engineering, 126(1), 518-526 
fTable 1. Test statistics for each dependent and independent variables $\div$ : W $(m)$ :indicated embedding dimension; $95 \%$ C.I.:-indicated 95\% confidential inbound for test; and-rejected data are marked as-in bold-characterf.

\begin{tabular}{|c|c|c|c|c|c|c|c|c|}
\hline \multirow[b]{2}{*}{ Test Stat. } & \multirow[b]{2}{*}{ Value } & \multicolumn{7}{|c|}{ Dependent and independent variables } \\
\hline & & $\begin{array}{l}\text { Water Temp. } \\
\text { of U pstream }\end{array}$ & $\begin{array}{c}\text { Water Temp. } \\
\text { of } \\
\text { Downstream } \\
\text { (Target) }\end{array}$ & $\begin{array}{c}\text { A ir } \\
\text { Temp. }\end{array}$ & $\begin{array}{l}\text { Runoff } \\
\text { from } \\
\text { Fourchue } \\
\text { Ddam }\end{array}$ & $\begin{array}{c}\text { Solar } \\
\text { Radiation }\end{array}$ & $\begin{array}{l}\text { Relative } \\
\text { humidity }\end{array}$ & $\begin{array}{l}\text { Average } \\
\text { Wind } \\
\text { Speed }\end{array}$ \\
\hline $\begin{array}{l}\text { Levene's } \\
\text { test }\end{array}$ & $p$-value & 0.448 & 0.877 & 0.548 & 0.000 & 0.239 & 0.992 & 0.657 \\
\hline \multirow{2}{*}{$\begin{array}{c}\text { Lyapunov } \\
\text { exponent } \\
\text { Lamda } \\
\text { test }\end{array}$} & calculated & $1.82 \times 10^{-6}$ & $1.62 \times 10^{-6}$ & 0.000 & 1.000 & 0.0003 & 0.274 & 0.000 \\
\hline & 95\% C.I. & -0.0653 & -0.1486 & -0.3825 & 0.1245 & -0.1868 & -0.2372 & -0.6811 \\
\hline \multirow{5}{*}{ BDS test } & W(2) & 79.02 & 62.15 & 20.96 & 16.49 & 2.82 & 19.58 & 2.53 \\
\hline & W(3) & 85.80 & 67.11 & 20.30 & 15.17 & 0.81 & 18.29 & 2.42 \\
\hline & W(4) & 94.52 & 73.32 & 19.81 & 13.79 & 0.46 & 17.12 & 2.05 \\
\hline & W(5) & 106.87 & 82.27 & 19.86 & 12.74 & 0.54 & 16.62 & 1.74 \\
\hline & $95 \%$ C.I & \multicolumn{7}{|c|}{$[-1.96,+1.96]$} \\
\hline \multicolumn{2}{|c|}{ Result } & $\begin{array}{l}\text { Nonlinear } \\
\text { stochastic } \\
\text { time series }\end{array}$ & $\begin{array}{l}\text { Nonlinear } \\
\text { stochastic } \\
\text { time series }\end{array}$ & $\begin{array}{l}\mathrm{N} \text { onlin } \\
\text { ear } \\
\text { stochas } \\
\text { tic time } \\
\text { series }\end{array}$ & $\begin{array}{c}\text { Chaotic } \\
\text { time } \\
\text { series } \\
\text { with } \\
\text { hetero- } \\
\text { skedastici }\end{array}$ & m & $\begin{array}{c}\text { Chaotic } \\
\text { time } \\
\text { series }\end{array}$ & $\begin{array}{l}\text { Nonlinear } \\
\text { stochastic } \\
\text { time } \\
\text { series }\end{array}$ \\
\hline
\end{tabular}

Comment [F14]: Please edit tables: -remove [ ] from the caption and remove bold and italics (I have done Table 1 caption)

-remove shading/colour and all lines except horizontal line above and

below the table and below the header row

remove upper case initials except for

the first word in each heading unless proper noun, e.g. Dam

Formatted: Font: Not Bold

Formatted: Font: Not Italic

Formatted: Font: Not Italic

Formatted: Font: Not Italic

Formatted: Font: Not Italic

Formatted: Font: Not Italic

Comment [F15]: editing tables: -remove [ ] from the caption and remove bold and italics

-remove shading/colour and all lines except horizontal line above and below the table and below the

header row

-remove upper case initials except for the first word in each heading unless proper noun, e.g. Dam

Formatted: Font: Not Italic

Formatted: Font: Not Italic 
[Table 2. Calibration and validation performance statistics for each Case]

\begin{tabular}{c|c|c|c|c|c|c|c|}
\hline \multirow{2}{*}{ CASE } & \multirow{2}{*}{ M odel } & \multicolumn{3}{|c|}{ Calibration phase } & \multicolumn{3}{c|}{ Validation phase } \\
\cline { 3 - 8 } & & RMSE $\left({ }^{\circ} \mathrm{C}\right)$ & NASH & BIAS $\left({ }^{\circ} \mathrm{C}\right)$ & RM SE $\left({ }^{\circ} \mathrm{C}\right)$ & NASH & BIAS $\left({ }^{\circ} \mathrm{C}\right)$ \\
\hline \multirow{4}{*}{ CASE 1 } & CEQUEAU & 0.80 & 0.91 & -0.36 & 0.77 & 0.91 & -1.14 \\
\cline { 2 - 8 } & ARMAX & 0.57 & 0.96 & 0.04 & 0.68 & 0.94 & 0.82 \\
\cline { 2 - 8 } & NARX & 0.67 & 0.94 & 0.11 & 0.80 & 0.91 & 0.75 \\
\hline \multirow{4}{*}{ CASE 2 } & CEQUEAU & 0.78 & 0.92 & -0.45 & 0.83 & 0.88 & -0.97 \\
\cline { 2 - 8 } & ARMAX & 0.55 & 0.96 & 0.01 & 1.14 & 0.83 & 1.60 \\
\cline { 2 - 8 } & NARX & 0.65 & 0.94 & -0.18 & 1.46 & 0.77 & 4.20 \\
\cline { 2 - 8 } & CEQUEAU & 0.79 & 0.92 & -0.41 & $\mathbf{0 . 8 0}$ & $\mathbf{0 . 9 0}$ & $\mathbf{- 1 . 0 6}$ \\
\cline { 2 - 8 } Rverall & ARMAX & $\mathbf{0 . 5 6}$ & $\mathbf{0 . 9 6}$ & $\mathbf{0 . 0 3}$ & 0.91 & $\mathbf{0 . 8 9}$ & $\mathbf{1 . 2 1}$ \\
\cline { 2 - 8 } & NARX & 0.66 & 0.94 & -0.18 & 1.13 & 0.84 & 2.48 \\
\hline
\end{tabular}



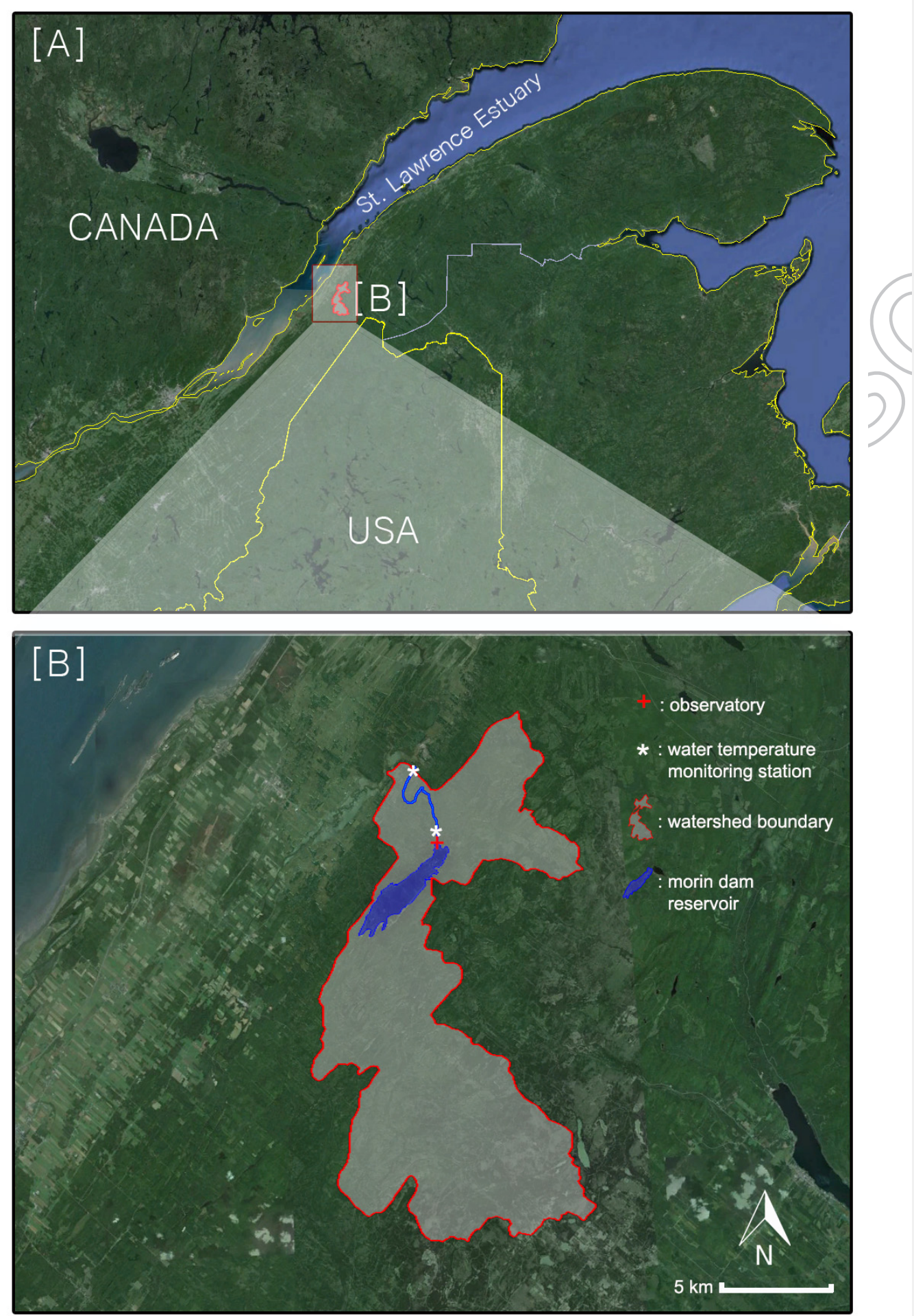

Fig. 1 Study area and measuring station. 

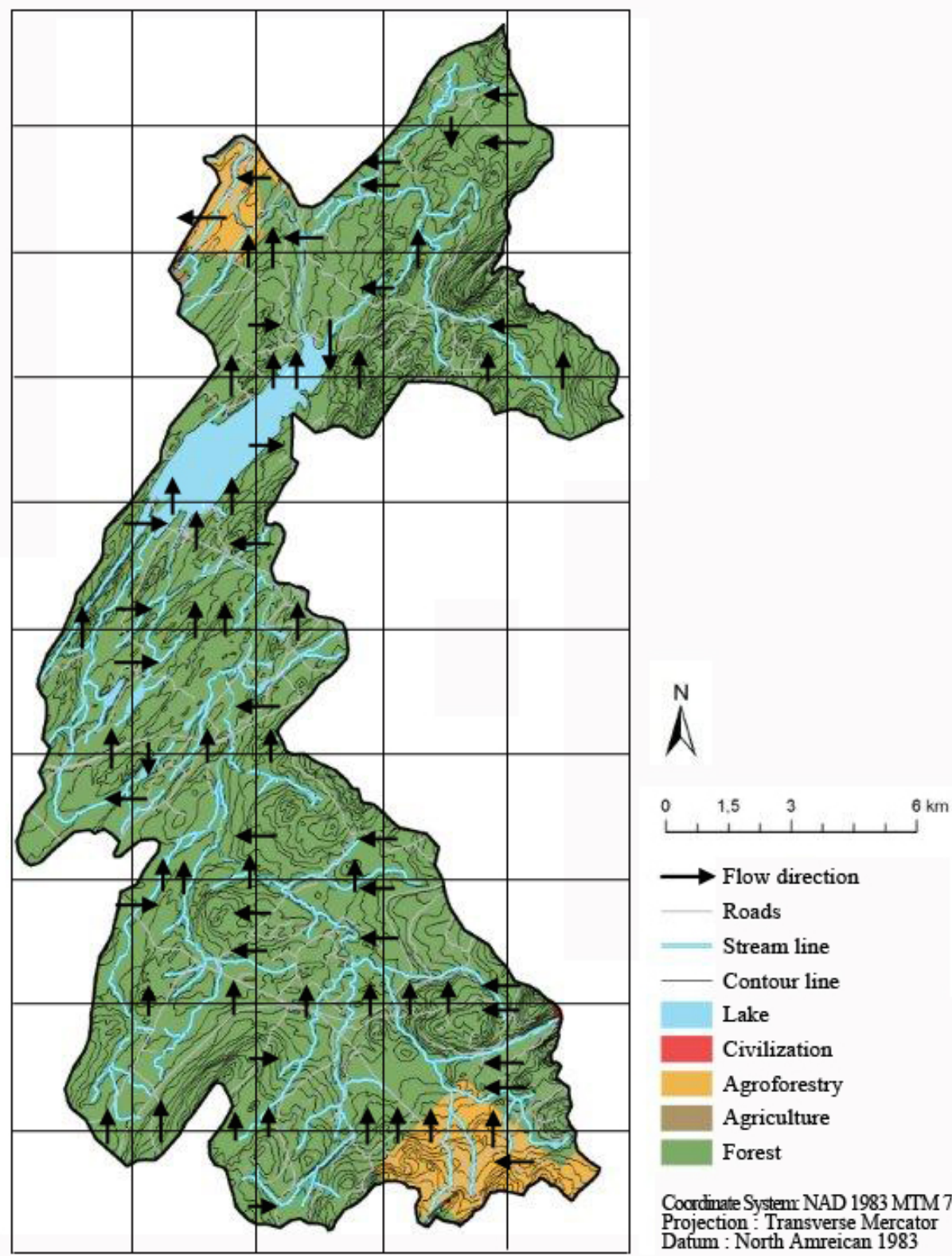

Fig. 2 Hydro-physiographical characteristics of study area. M ap shows land use, whole squares (elementary hydrological units) and arrows indicate water routing used for the deterministic (CEQUEAU) model. 
(a)

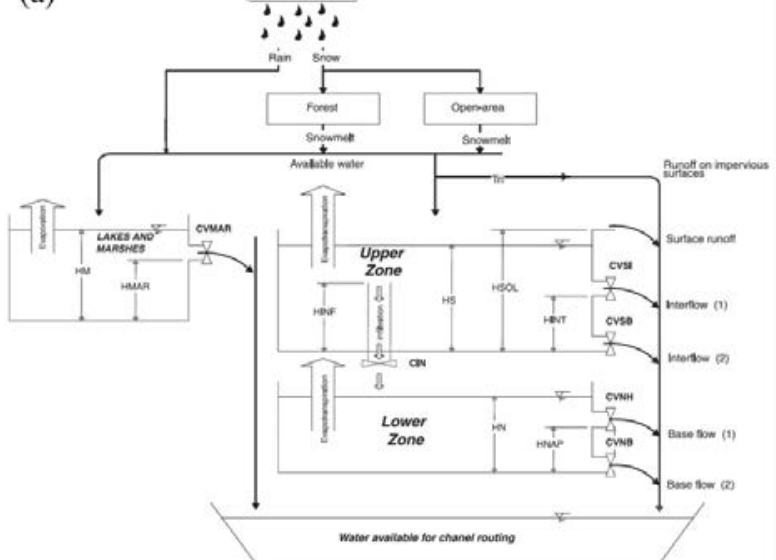

(b)
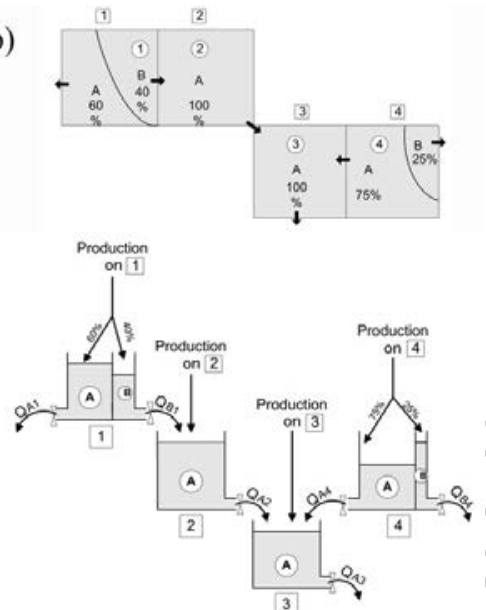

Fig. 3 Schematic description of CEQUEAU model; (a) production function (b) routing function (M orin, 2007).

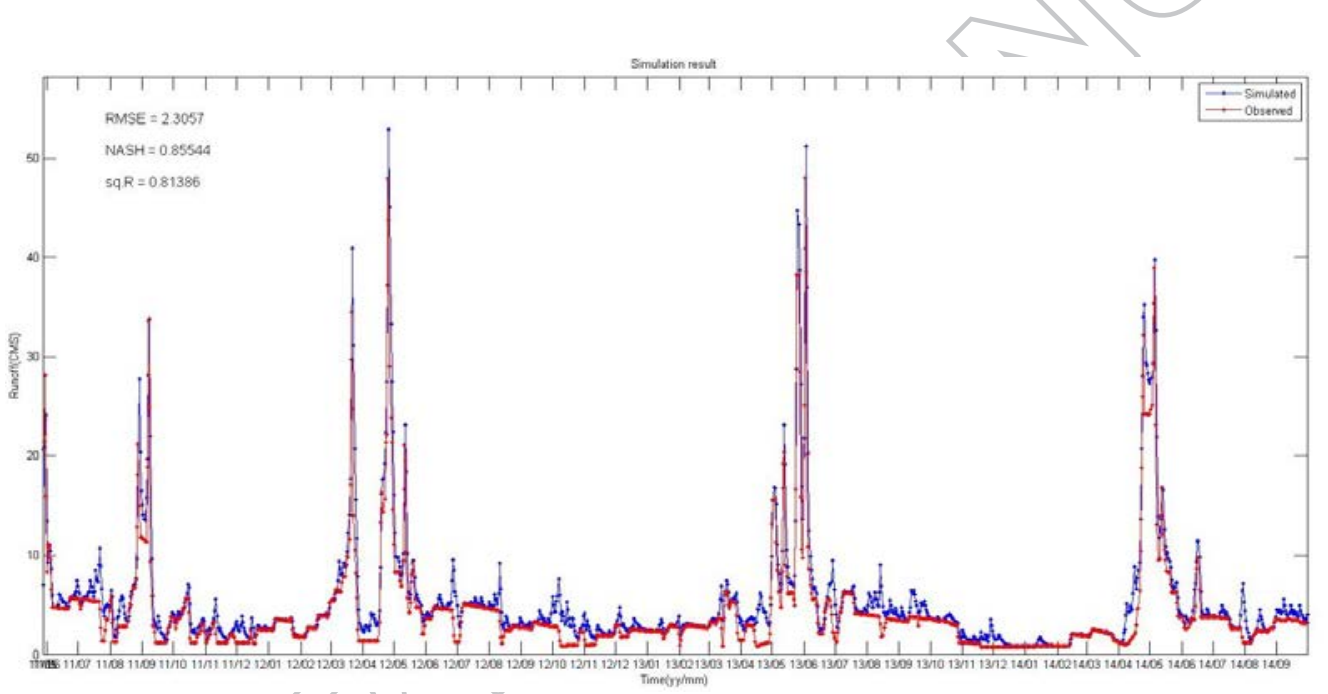

Fig. 40 bserved and simulated flows with CEQUEAU hydrological model for both calibration and validation periods (J une, 2011 to September, 2014). 


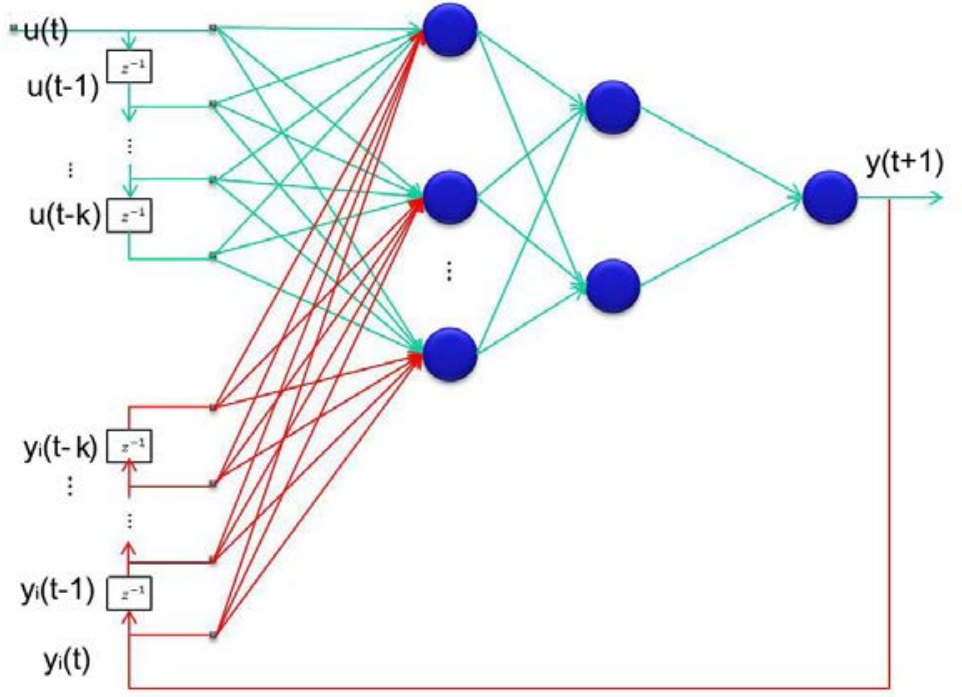

Fig. 5 NARX network schematization (Jose et al., 2008). $u(t)$ is the input set, $y_{i}(t)$ is the exogeneous input, $\mathrm{k}$ is the input delay and each circle represents an artificial neuron. 
(a)

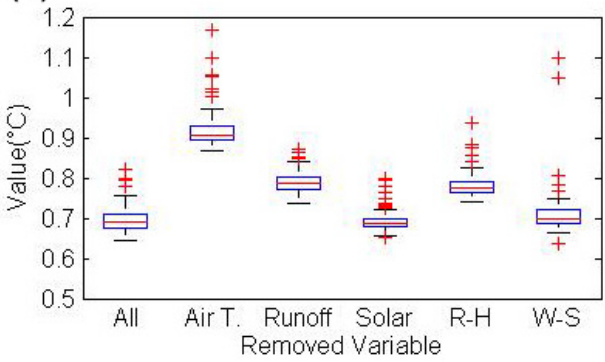

(c)

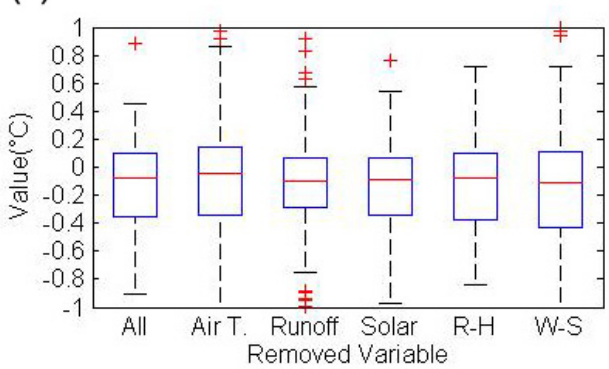

(e)

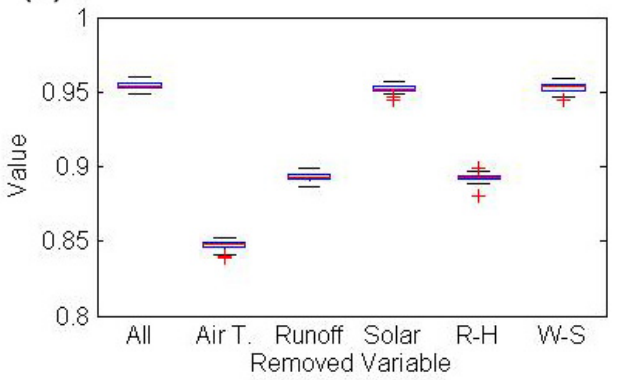

(b)

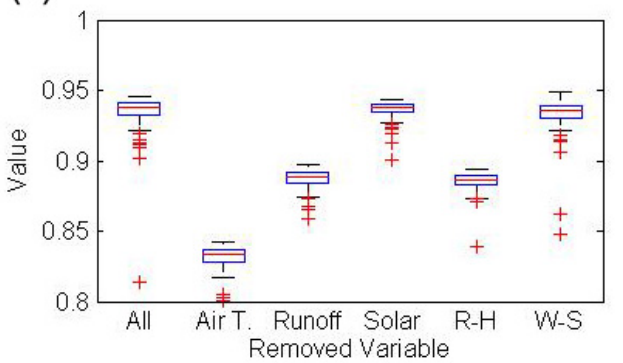

(d)

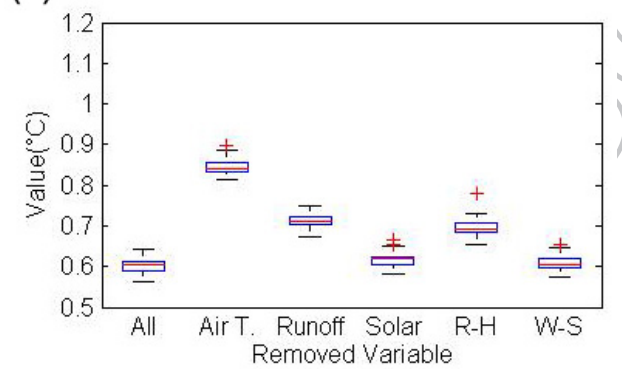

(f)

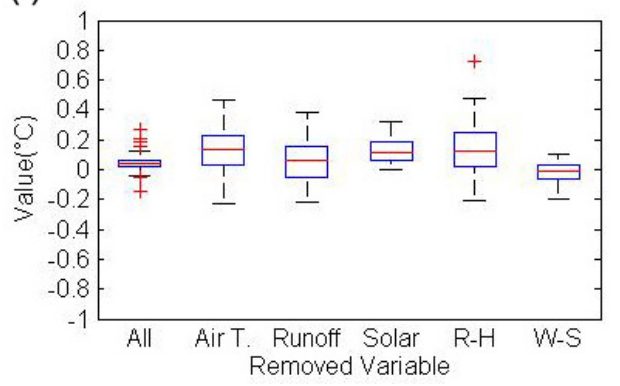

Fig. 6 Performance statistics from jackknife simulations to select predictor; (a)

RMSE of NARX, (b) Nash of NARX, (c) Bias of NARX, (d) RMSE of ARMAX, (e) Nash of ARMAX, (f) Bias of ARMAX. 
(a)

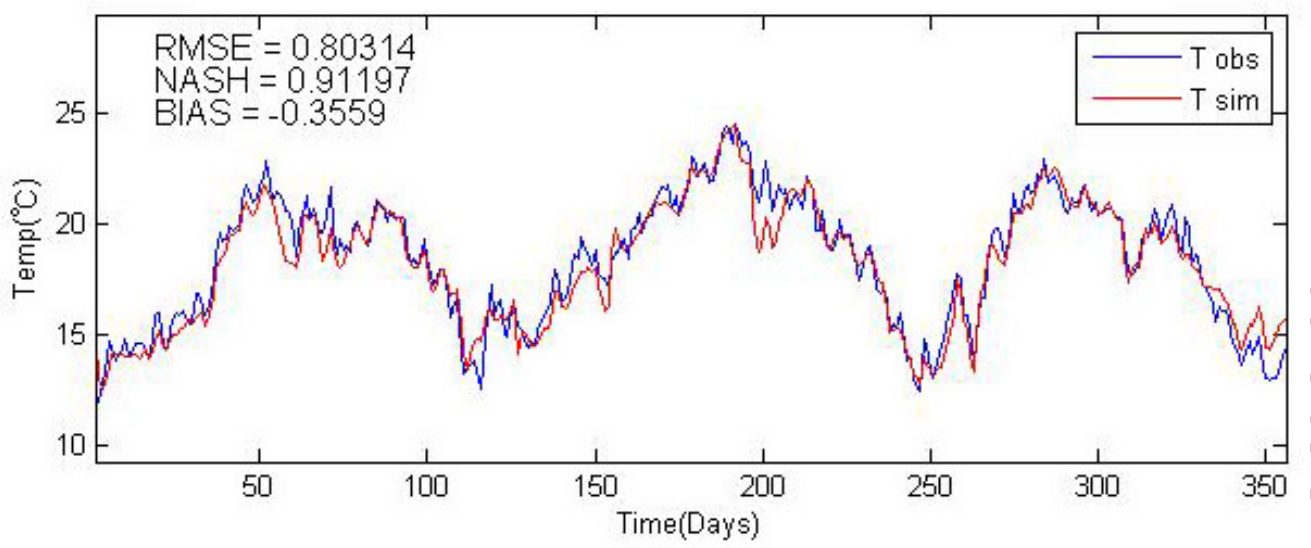

(b)

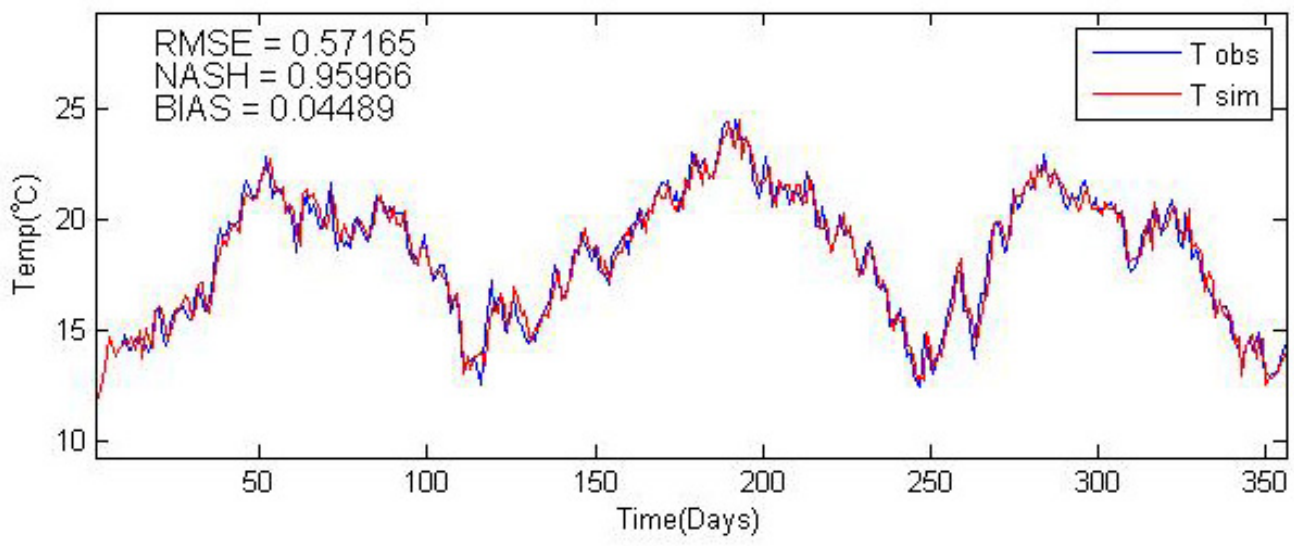

(c)

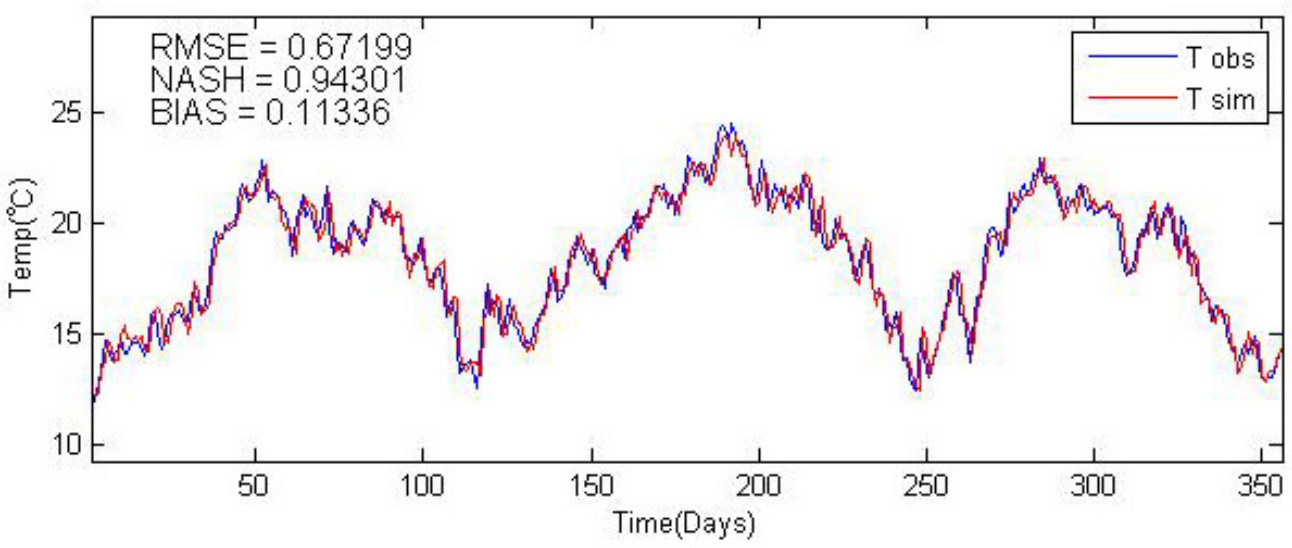

Fig. 7 Calibration results for Case 1; (a) CEQUEAU model, (b) ARMAX, (c) NARX. 
(a)

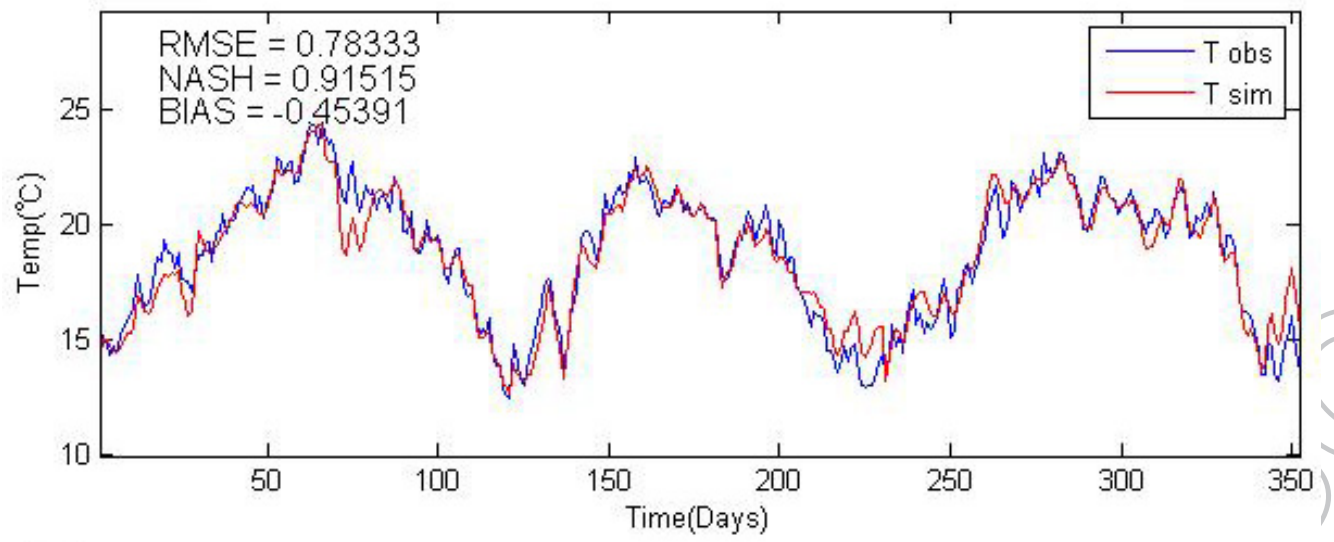

(b)

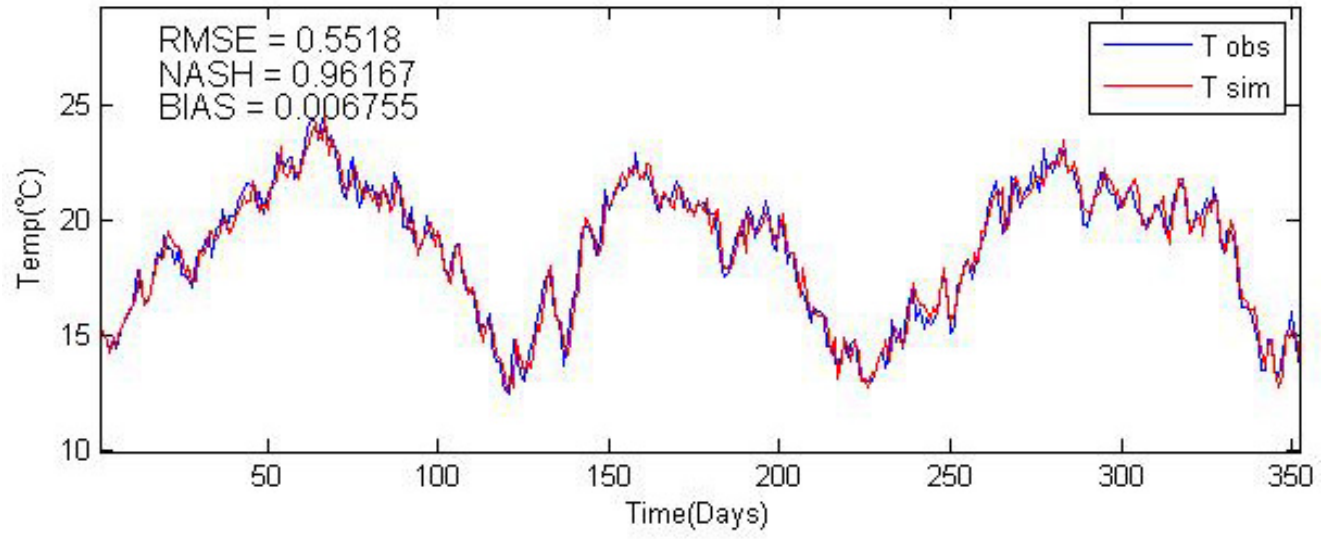

(c)

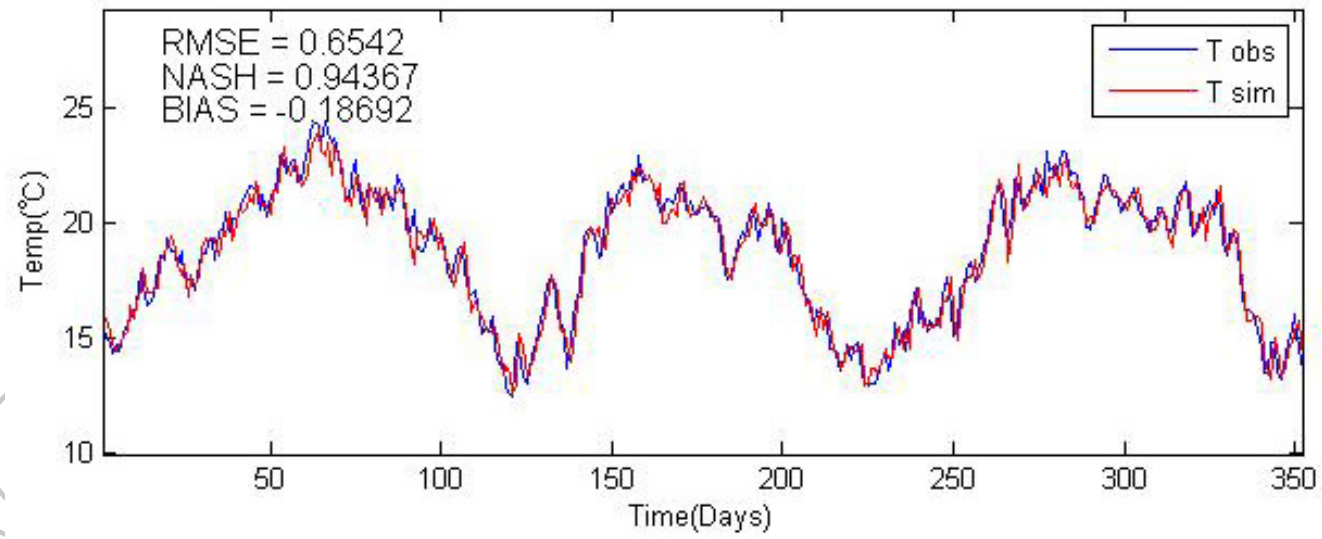

Fig. 8 Calibration results for Case 2; (a) CEQUEAU model, (b) ARMAX, (c) NARX. 
(a)

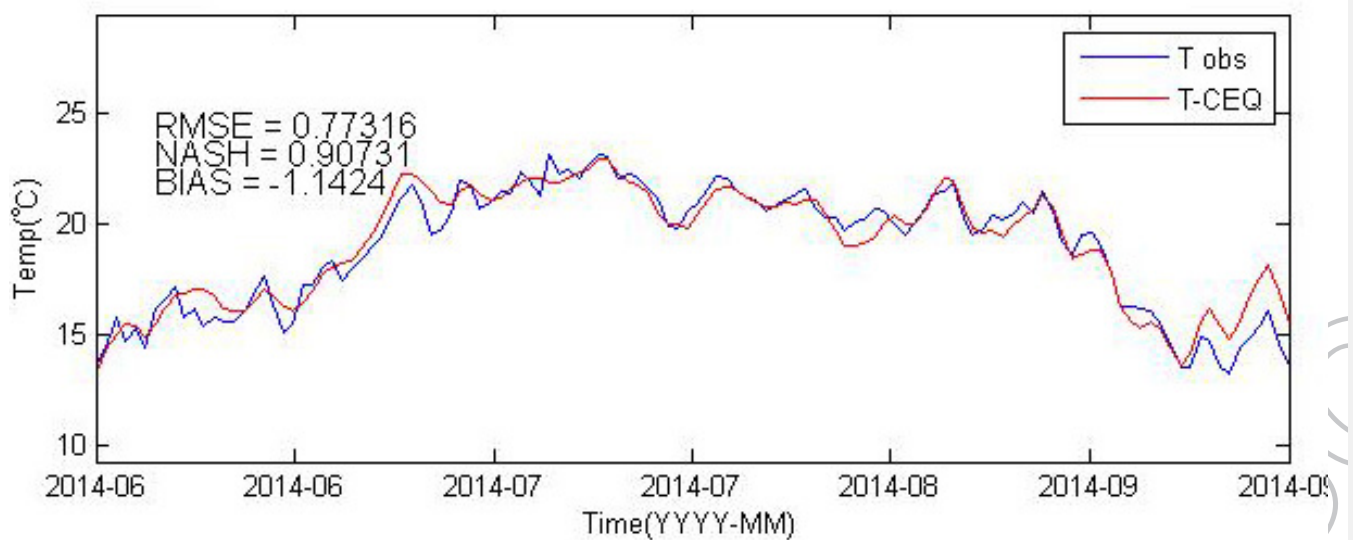

(b)

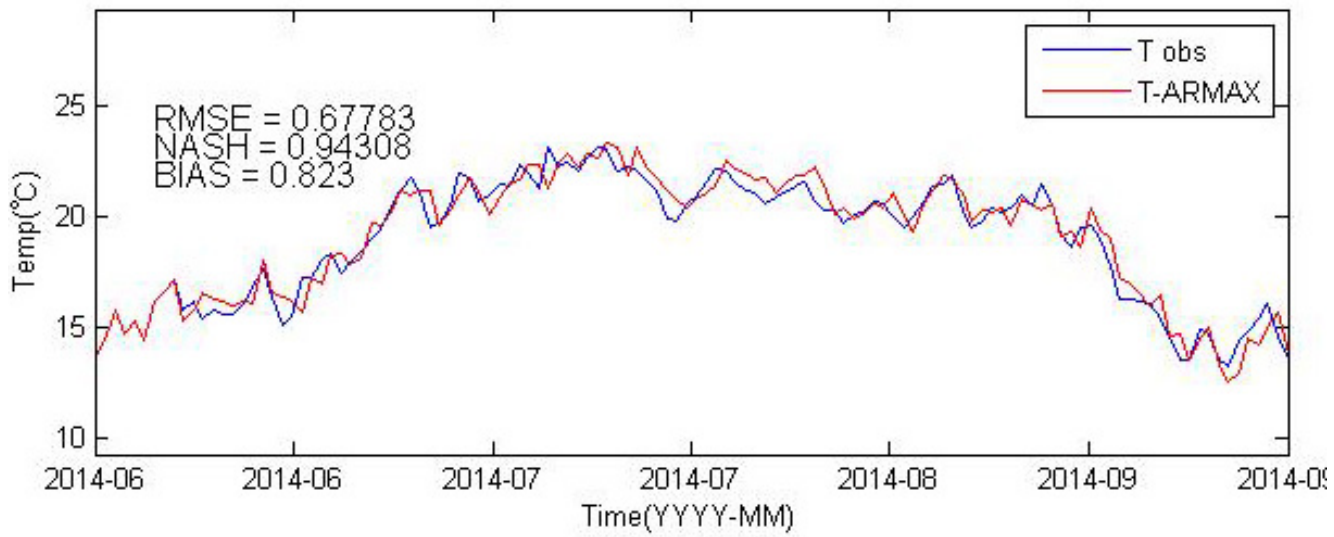

(c)

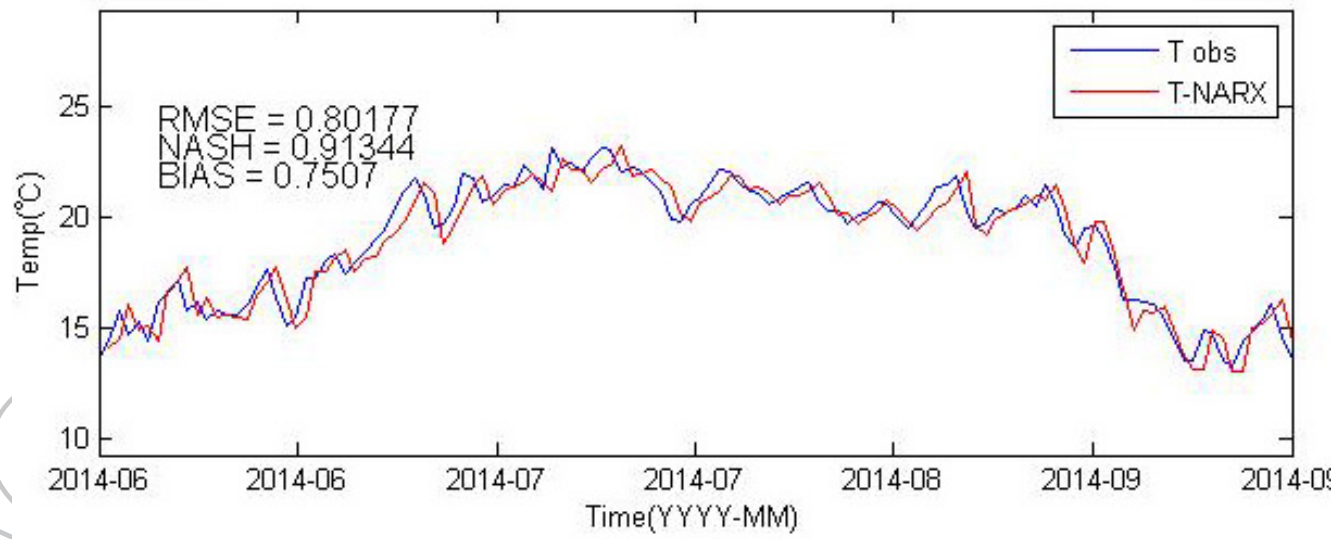

Fig. 9 Validation results for Case 1; (a) CEQUEAU model, (b) ARMAX, (c) NARX. 
(a)

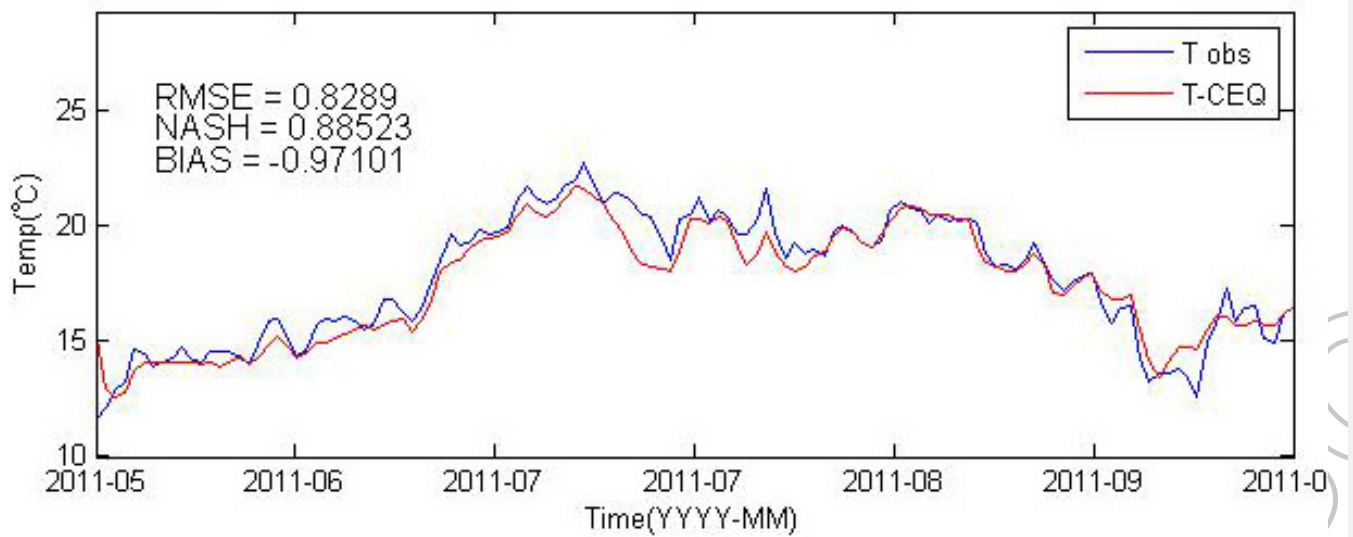

(b)

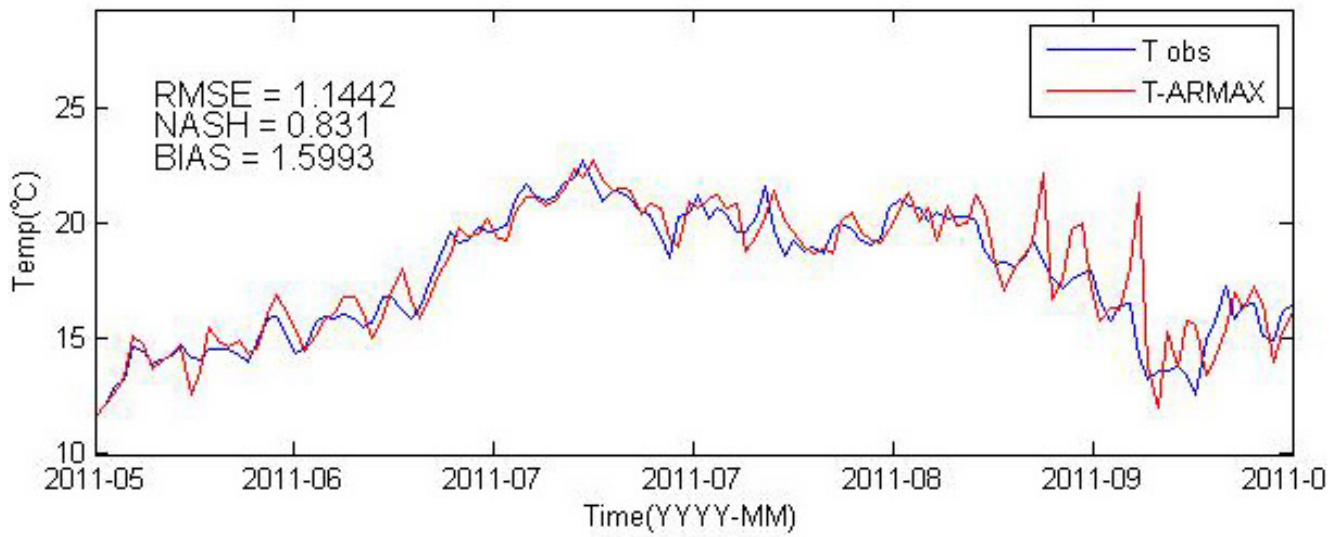

(c)

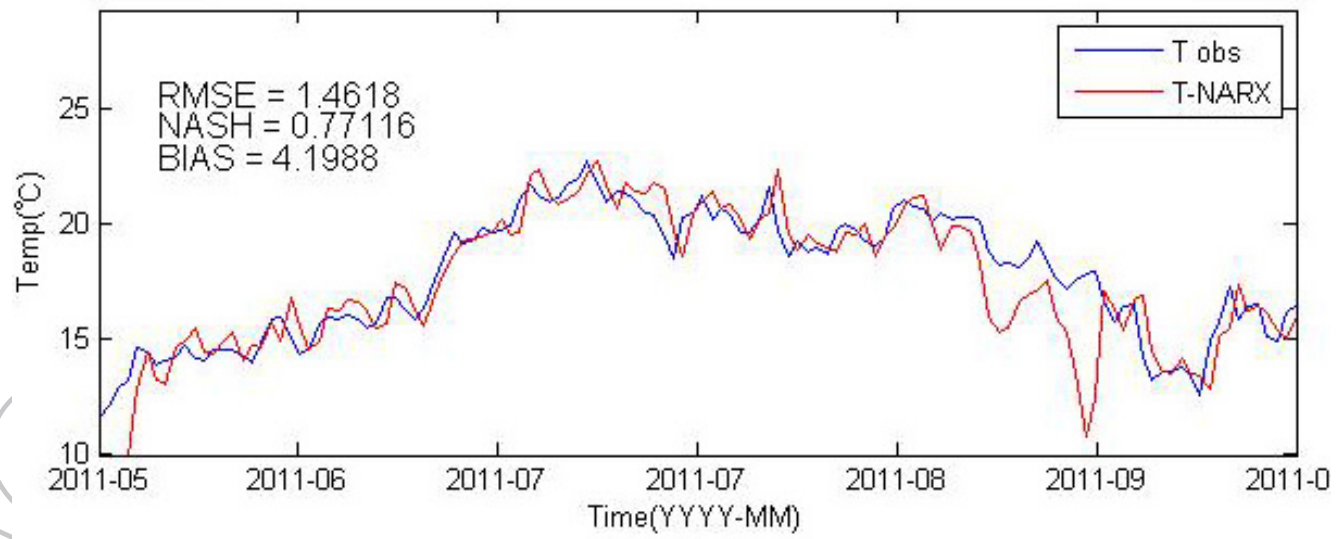

Fig. 10 Validation results for Case 2; (a) CEQUEAU model, (b) ARMAX, (c) NARX. 